\title{
Pain modulation and Histopathological effects of the Hydroalcoholic extract of Capparis spinosa on mice model of Orofacial formalin test: an experimental study
}

\author{
Arezou Rayyani ${ }^{1}$, Safoura Seifi ${ }^{2}$, Roja Askian ${ }^{3}$, Manouchehr Ashrafpour ${ }^{4}$, Sohrab Kazemi ${ }^{5}$, Ali Akbar \\ Moghadamnia $^{6}$, Hemmat Gholinia ${ }^{7}$
}

1 Assistant Professor of Oral and Maxillofacial Pathology, Bandarabbas University of Medical Sciences, Bandarabbas, Iran

${ }^{2}$ Oral Health Research Center, Institute of Health, Faculty of Dentistry, Babol University of Medical Sciences, Babol, Iran

${ }^{3}$ Student Research Center of Babol University of Medical Sciences, Babol, Iran

${ }^{4}$ Associate Professor of Physiology and Pharmacology, Babol University of Medical Sciences, Babol, Iran

${ }^{5}$ Neuroscience Research Center, Health Research Center, Babol University of Medical Sciences, Babol, Iran

${ }^{6}$ Department of Pharmacology, Faculty of Medicine, Babol University of Medical Sciences, Babol, Iran

${ }^{7}$ M.Sc. of Statistics, Health Research Center, Babol University of Medical Sciences, Babol, Iran

\section{Type of article: Original}

\begin{abstract}
Background: Orofacial pain is a form of inflammatory pain usually treated with corticosteroids, which have many side effects.

Objective: The aim of this study was to investigate the clinical and histological profile of antinociceptive effects of hydroalcoholic extract of caper (Capparis spinosa) for the first time in the orofacial region.

Methods: This experimental study was carried out at Babol University of Medical Sciences in 2018. Thirty-six male Wistar mice were divided into 6 groups: The first group received saline, the second group received dexamethazone, and four groups received different doses $(10,20,50,100 \mathrm{mg} / \mathrm{kg})$ of caper extract. In the formalin test, $1 \%$ formalin solution was injected into the right submucosal layer of the lip and lateral area of the nose. Pain intensities were recorded at 5-min blocks for $60 \mathrm{~min}$ after injection. Dose effect of caper on pain was recorded. The mice were euthanized and the oral area was biopsied and stained with Hematoxylin-eosin, Toluidine blue, and Congo red. Data were analyzed using repeated measures ANOVA and t-test by IBM-SPSS version 20.

Results: Caper produced antinociceptive effects in comparison with saline groups $(\mathrm{p}<0.001)$. Dose effect on pain was significant $(p<0.001)$. The highest antinociceptive effect was observed in the caper group receiving 100 $\mathrm{mg} / \mathrm{kg}$ of agent 15-20 minutes after injection. The highest pain level was observed in the group that received 20 $\mathrm{mg} / \mathrm{kg}$ of caper $(\mathrm{p}<0.001)$. Dexamethazone antinociceptive effect was greater than that of the saline and the dose of $20 \mathrm{mg} / \mathrm{kg}$ of caper $(\mathrm{p}<0.001)$. Antinociceptive effects in two groups $(100 \mathrm{mg}$ caper and dexamethazone) were equal ( $>0.999)$. Histopathologic examination revealed the highest thickness of epithelium, fibrous, and muscular tissue density and the lowest inflammatory infiltration at the dose of $100 \mathrm{mg} / \mathrm{kg}$ of caper.

Conclusion: The results of the present study suggest that hydroalcoholic extract of caper possesses antinociceptive activity in a dose-dependent manner and caper-induced antinociception might be mediated, at least in part, by anti-inflammatory effects.
\end{abstract}

Keywords: Caper, Orofacial pain, Formalin test, Histopathology, Antinociception

\section{Abbreviations / Acronyms:}

TMD: Temporomandibular Disorders

\section{Corresponding author:}

Safoura Seifi, Oral Health Research Center, Institue of Health, Faculty of Dentistry, Babol University of Medical Sciences, Babol, Iran. Tel: +98.1132291408-9, Fax:+98.1132291093, E-mail: sf_seify@yahoo.com

Received: September 26, 2018, Accepted: June 25, 2019, Published: September 2019

iThenticate screening: June 25, 2019, English editing: August 14, 2019, Quality control: August 22, 2019

This article has been reviewed / commented by four experts

Ethics approval: Ethics Committee of Babol University of Medical Sciences (Ref: MUBABOL.REC.1394.268)

(C) 2019 The Authors. This is an open access article under the terms of the Creative Commons Attribution-NonCommercialNoDerivs License, which permits use and distribution in any medium, provided the original work is properly cited, the use is non-commercial and no modifications or adaptations are made. 


\section{Introduction}

Pain is an unpleasant form of compensatory response to tissue damage. Orofacial pain is usually caused by any irreversible damage to the tissues by free radicals and increase in production of inflammatory mediators (1). Orofacial pain that is felt in the mouth, face, and head include inflammatory pains such as pulp pain, temporomandibular disorders (TMD), trigeminal neuralgia, facial atypical pains, oral burning syndrome, pain due to cancer, and periodontal problems that cause disability, weakness, and discomfort for the patient (2). The trigeminal nerve and its ganglion innervate the orofacial region (3). Failure to recognize the mechanism of inflammatory and neurological pain leads to inability to provide adequate pain management (4).

Although nowadays opioids, antidepressants, and non-steroid anti-inflammatory drugs are used in the treatment of chronic orofacial pain, their application is not satisfactory due to their adverse side effects. Long-term use of opioids leads to dependence, euphoria, and tolerance. Long-term treatment or high levels of corticosteroids may result in indigestion, muscle weakness, fluid retention, stomach bleeding, osteoporosis, obesity, heart failure, respiratory problems, anemia, liver damage, and Stevens-Johnson syndrome (5-7). Therefore, researchers have suggested use of traditional medicine as a tried and useful method of pain and inflammation management (8).

The caper bush (Capparis spinosa) is a plant used in traditional medicine, which is native to central and western Asia and circum-Mediterranean countries including Iran, Cyprus, Greece, and Turkey. In Iran, it grows in dry and warm areas, especially in Baluchestan, Kerman, Ilam, Bushehr, and Yazd. In traditional medicine, the leaves, roots, and flower buds are used in the treatment of diabetes, rheumatism, abdominal pain, and cancer due to their effects in enhancement of the function of the immune system and anti-inflammatory, antibacterial, anti-viral, antioxidant, and anti-obesity effects. The plant is also effective in differentiating chondrocytes and bone repair $(8,9)$.

Most previous studies have investigated the anti-inflammatory and antioxidant properties of caper (8-10). Orofacial formalin test is a practical, repeatable, and easy method that can be used to quantitatively measure the antinociceptive effect of a drug in the trigeminal region in mice (11). Since the mechanism of action of caper is not fully understood, in this study, the clinical and histological effects of caper on orofacial pain were evaluated.

\section{Material and Methods}

\subsection{Research design}

In this experimental study, 36 male Wistar mice (12 male) (weighing approximately 18-24 g) were studied in a laboratory of Babol University of Medical Sciences in 2018. The animals were kept in a calm and isolated room (the light/dark cycle was set at 12:12 hours) in separate cages with easy access to water and food. The laboratory temperature and humidity was kept at $23 \pm 2{ }^{\circ} \mathrm{C}$ and $50 \%$, respectively. The animals were divided into six groups, which included a saline group (negative control) that received intraperitoneal injection of normal saline $(0.1 \mathrm{mg} / \mathrm{kg})$, the same volume of caper, 30 minutes before the formalin test. The treatment groups received intraperitoneal caper extracts at doses of $10,20,50,100 \mathrm{mg} / \mathrm{kg}, 30$ minutes before the formalin test (11). The positive control group (group 6) received intraperitoneal dexamethazone $(10 \mathrm{mg} / \mathrm{kg})$.

\subsection{Preparation of caper hydroalcoholic extract}

First, $320 \mathrm{~g}$ of stems and leaves of the caper bush were dried separately at $25{ }^{\circ} \mathrm{C}$. Then, they were powdered in a grinder and $100 \mathrm{~g}$ of powder was added to one liter of argon and ethyl alcohol $75 \%$ was added. The solution was filtered after 72 hours and condensed in a vacuum distillation machine at $50{ }^{\circ} \mathrm{C}$ and a rotary speed of $70 \mathrm{rpm}$ to $1 / 3$ of its initial volume. Using a percolation method, a $50 \mathrm{cc}$ extract was obtained. The extract was diluted with saline for later use (11). All the extraction steps were performed in sterile containers and the extract was autoclaved at the end of the extraction process. To prepare different concentrations of caper extract based on the weight of the animals in each group, a certain amount of the extract was weighed and then dissolved in an appropriate amount of sterile saline, given that the volume of injection was $10 \mathrm{ml} / \mathrm{kg}$. Each animal was injected with the diluted caper solution in proportion to its weight.

\subsection{Formalin test}

The formalin test is a standard test for measuring pain response and is determined by the sum of time (in seconds) that the animal scratches, licks, or bites the formalin injection site. The times are measured every 5 minutes, and the numerical value represents the amount of pain $(12,13)$. After placing the animal on a glass plate, $2 \%$ formalin at a volume of $50 \mu \mathrm{L}$ was injected into the right submucosal tissue of the upper lip, lateral to the nose using a 26 gauge needle. Pain intensities were recorded at 5-min blocks for $60 \mathrm{~min}$ after injection. The severity of pain was calculated 
based on the number of times the animal scratched its lip by foot or hand, and photographed by a camera attached to a computer (14).

\subsection{Histopathological evaluation}

The mice were then euthanized and biopsy was prepared from their lips. The severity of inflammatory infiltration was considered qualitatively (as mild, moderate, and severe). Blood vessel density was measured by Hematoxylineosin staining, mast cell density was determined by Toluidine blue staining and eosinophil distribution was evaluated by Congo red staining. The mean density of mast cells was measured in 4 microscopic fields with (x40) (15). The mean density of eosinophils was measured in 10 microscopic fields (x40) (16).

\subsection{Statistical analysis}

The results were recorded in IBMC SPSS $\odot$ Statistics version 20 (IBM $\odot$ Corp., Armonk, NY, USA) and analyzed using repeated measures ANOVA and t-test. P-value $<0.05$ was considered significant.

\subsection{Ethics of research}

This study was approved by the Ethics Committee of Babol University of Medical Sciences (Ref: MUBABOL.REC.1394.268).

\section{Results}

\subsection{Pain modulatory effects of Capparis spinosa extract}

The effects of different doses of caper were evaluated at different times and compared with the saline group. There was a statistically significant difference between the caper group and the saline group. Caper reduced pain compared to the saline group. The dose effect on the pain measured at different times was significant $(\mathrm{df}=6, \mathrm{~F}=11.9, \mathrm{p}<0.001)$. The severity of pain in the dexamethazone group was lower than that of the saline group and the group receiving caper extract at $20 \mathrm{mg} / \mathrm{kg}(\mathrm{p}<0.001)$. The highest antinociceptive effect was observed in the caper group at 100 $\mathrm{mg} / \mathrm{kg}$, with the dexamethazone recipient group coming after that, but the difference was not statistically significant $(\mathrm{p}>0.05)$. In terms of time, the highest pain reduction was observed in all the groups at 15-20 minutes. The highest and lowest pain severity were observed in the groups that received 20 and $100 \mathrm{mg} / \mathrm{kg}$ of caper, respectively (Table 1 , Figure 1).

\subsection{Histopathological findings}

\subsubsection{Hematoxylin-eosin staining}

The highest density of fibrous and muscle tissues and the highest epithelium thickness, which are signs of tissue repair, were observed at the dose of $100 \mathrm{mg} / \mathrm{kg}$ of caper. The lowest collagen density and loose connective tissue and myxomatous and the lowest thickness of epithelium and muscle tissue were observed at the dose of $20 \mathrm{mg} / \mathrm{kg}$ of caper (Figure 2).

\subsubsection{Inflammatory infiltration:}

The lowest inflammatory infiltration was observed at the dose of $10 \mathrm{mg} / \mathrm{kg}$ of caper and the highest chronic inflammatory infiltration was observed at the dose of $20 \mathrm{mg} / \mathrm{kg}(\mathrm{p}<0.001)$

\subsubsection{Blood vessel density}

The lowest blood vessel density was observed in the group that received $100 \mathrm{mg} / \mathrm{kg}$ of caper extract. However, no statistically significant difference was observed between the groups $(\mathrm{p}=0.057)$.

Table 1. Mean value of pain (number of rubbing) in acute (0-5 minutes) and chronic pain (6-60 minutes)

\begin{tabular}{|l|l|l|l|l|l|l|}
\hline \multirow{2}{*}{ Treatment } & \multicolumn{7}{l|}{ Time (minutes) } \\
\cline { 2 - 7 } & $0-5$ & $20-25$ & $30-35$ & $40-45$ & $50-55$ & $60-65$ \\
\hline Saline & $35 \pm 12.2$ & $33 \pm 16.9$ & $23.5 \pm 18.6$ & $33.3 \pm 33.03$ & $19.8 \pm 39.4$ & $12.3 \pm 17.5$ \\
\hline Dexamethazone & $0.33 \pm 0.81$ & $9 \pm 9.91$ & $4.5 \pm 5.54$ & $2.33 \pm 2.33$ & $1.3 \pm 2.8$ & $1.3 \pm 3.2$ \\
\hline 10 & $0.83 \pm 2.04$ & $6.6 \pm 6.1$ & $2.1 \pm 4.4$ & $15.3 \pm 8.04$ & $3.3 \pm 5.2$ & $7.3 \pm 11.6$ \\
\hline 20 & $47.3 \pm 25.4$ & $36.6 \pm 16.6$ & $4 \pm 5.05$ & $6.1 \pm 6.6$ & $53.3 \pm 36.5$ & $32 \pm 62.6$ \\
\hline 50 & $16.3 \pm 10.8$ & $7.3 \pm 6.5$ & $23.5 \pm 20.7$ & $9.5 \pm 6.5$ & $8.6 \pm 11.8$ & $2 \pm 3.1$ \\
\hline 100 & $2.33 \pm 3.6$ & $4.5 \pm 5.8$ & $6.5 \pm 10.4$ & $8.3 \pm 13.2$ & 0 & $1 \pm 2.4$ \\
\hline p-value & $<0.001$ & $<0.001$ & 0.009 & 0.023 & 0.002 & 0.346 \\
\hline
\end{tabular}




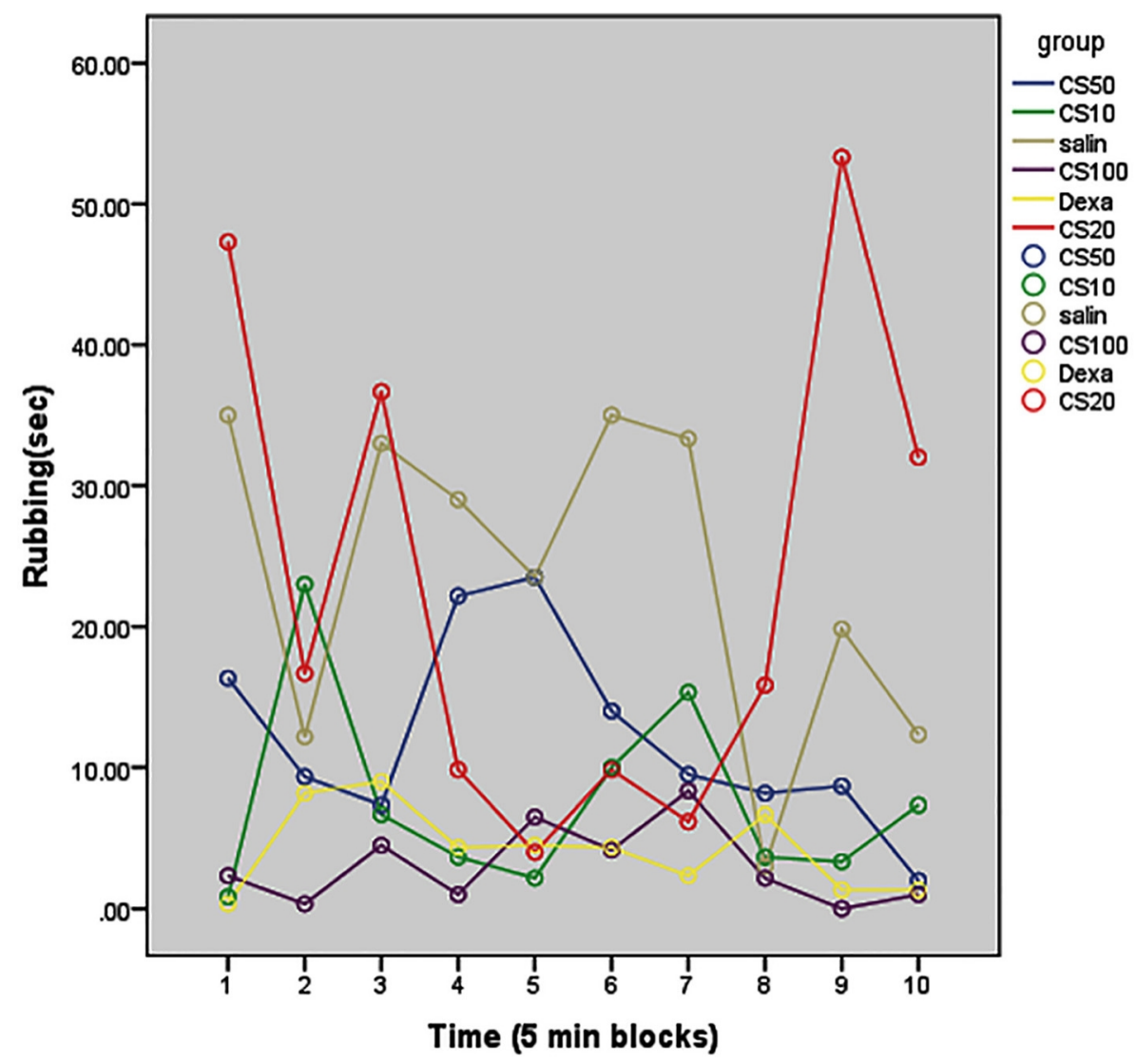

Figure 1. Comparison of mean value of pain (number of rubbing) in 6 groups in acute and chronic phase (saline, dexamethazone, caper $10,20,50,100)$
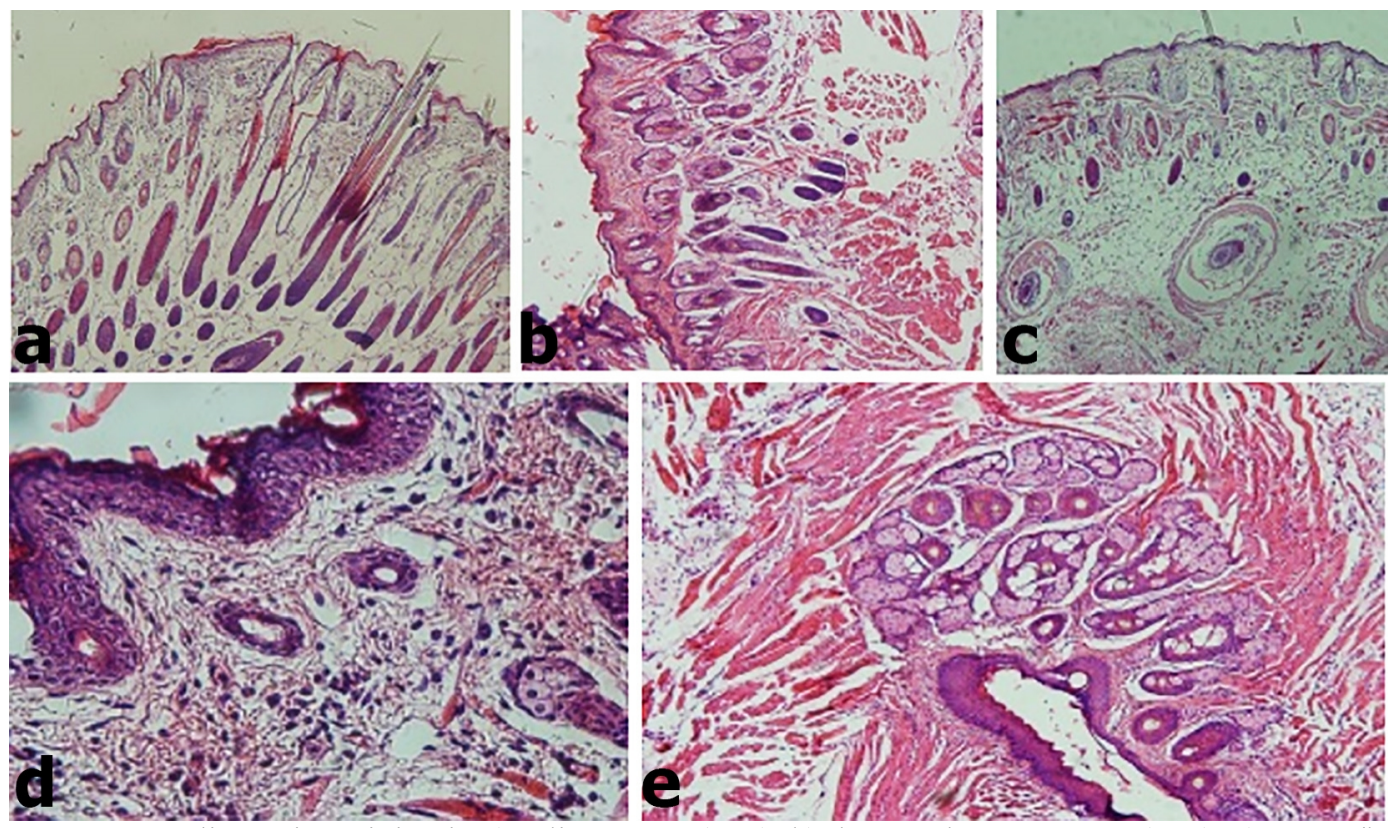

Figure 2. Hematoxylin-eosin staining in a) saline group (x10), b) dexamethasone group (x10), c) $20 \mathrm{mg} / \mathrm{kg}$ caper group (x10), Loose connective tissue was seen, d) $100 \mathrm{mg} / \mathrm{kg}$ caper group (x10), Fibrous connective tissue was seen, e) $100 \mathrm{mg} / \mathrm{kg}$ caper group (x40), Fibrous connective tissue was seen 


\subsection{Toluidine blue staining (mast cell density)}

Although the highest density of mast cells was observed in the group receiving $20 \mathrm{mg} / \mathrm{kg}$ of caper extract, there was no statistically significant difference between the groups regarding the density of mast cells $(\mathrm{p}=0.084)$ (Figure 3 ).
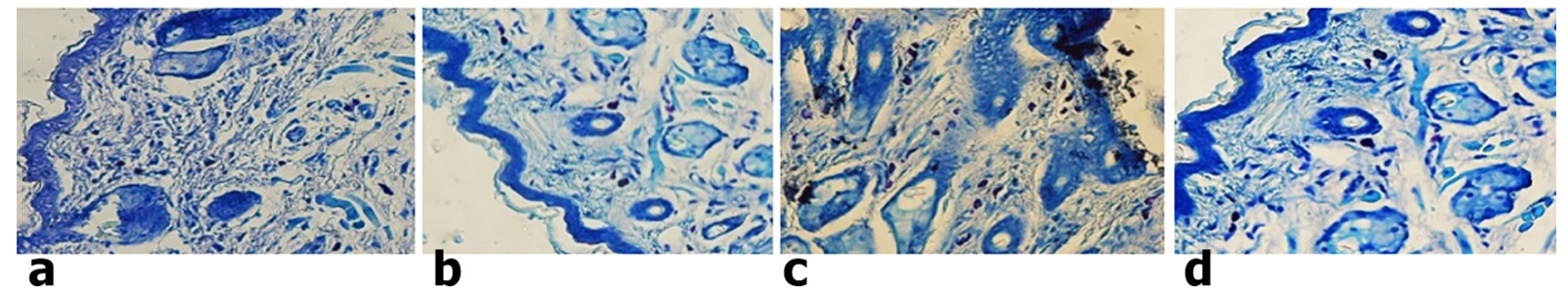

Figure 3. Toluidine blue staining in a) saline group (x10), b) dexamethazone group (x10), c) $20 \mathrm{mg} / \mathrm{kg}$ caper group (x40), increased mast cell density in connective tissue was seen, d) $100 \mathrm{mg} / \mathrm{kg}$ caper group (x40), decreased mast cell density in connective tissue was seen

\subsection{Congo red staining (eosinophil density)}

Except for a few eosinophils that were observed in the $20 \mathrm{mg} / \mathrm{kg}$ group, no eosinophils were observed in the microscopic slides. There was no statistically significant difference between groups in terms of eosinophil density $(\mathrm{p}>0.05)$ (Figure 4).
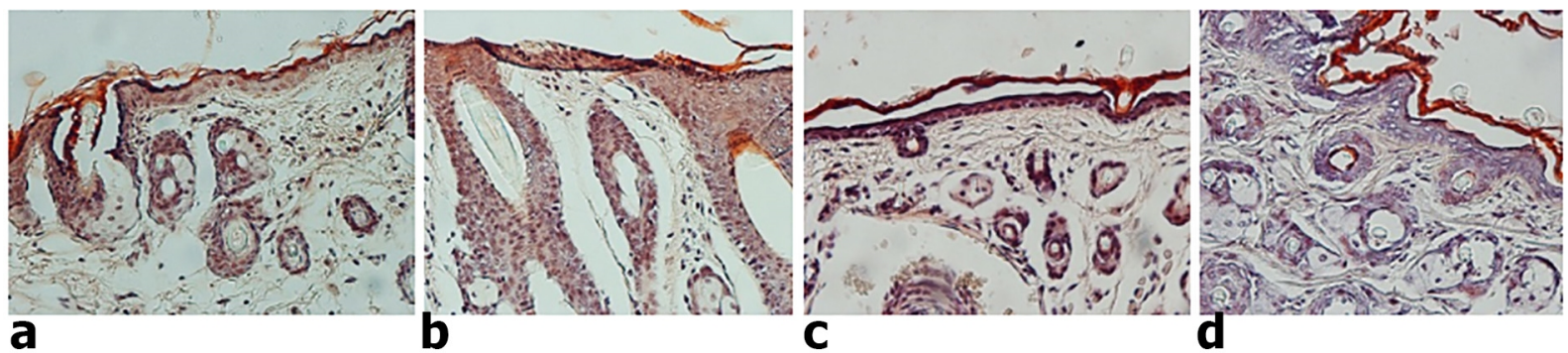

Figure 4. Congo red staining in a) saline group (x10), No evidence of eosinophil, b) dexamethazone group (x10), No evidence of eosinophil, c) $20 \mathrm{mg} / \mathrm{kg}$ caper groups (x40), No evidence of eosinophil, d) $100 \mathrm{mg} / \mathrm{kg}$ caper groups (x40), No evidence of eosinophil

\section{Discussion}

Today, NSAIDS are used for control of pain. These drugs have many side effects and drug dependence. Medicinal plants have many therapeutic effects and low side effects. These are available and inexpensive. Thus, much attention has been paid toward herbal therapy. Capparis spinosa is a plant which is used in herbal therapy. Capers have antioxidant and anti-inflammatory effects (5-7); but their antinociceptive effects have not proven in orofacial pain. From the results of this study, it seems that caper hydroalcoholic extract has antinociceptive effects in orofacial pain and its effect is dose-dependent, in that the highest antinociceptive effect was observed at the dose of $100 \mathrm{mg} / \mathrm{kg}$ and at 15-20 minutes. In other words, the mechanism of effect of caper hydroalcoholic extract is to stop the pain in the second phase. Gandomani et al. reported that Avicenia Marina in mice has anti-nociceptive properties with formalin test. They confirmed its effect may be because of flavonoid and tann compounds in plants, which have antinociceptive effects (17). The results of their studies are consistent with our findings. Arslan et al. reported that methanol extract of Capparis ovata has antinociceptive effects both at the peripheral and central levels. Its antinociceptive effect is at the dose of $50 \mathrm{mg} / \mathrm{kg}$. In our study, antinociceptive effect of caper was at the dose of 100 $\mathrm{mg} / \mathrm{kg}$ (18). It is argued that the main cause of orofacial pain is the release of inflammatory mediators in the region. The caper extract has anti-inflammatory function because of the presence of flavonoids (11). In the histopathologic section of this study, the highest anti-inflammatory effect was observed at the dose of $10 \mathrm{mg} / \mathrm{kg}$ of caper. Flavonoids are found in the leaves and roots of plants and can pass the blood-brain barrier and exert their antinociceptive effects through central alpha-adrenergic and GABAergic receptors. They inhibit cyclooxygenase in damaged tissues and prevent the production of prostaglandins (17). Shen et al. suggested (19) that flavonoids inhibit prostaglandin E production from arachidonic acid by inhibiting tumor necrosis factor and cyclooxygenase. Flavonoids reduce calcium accumulation in cells, which leads to a decrease in the activity of the nitric oxide synthase and phospholipase $\mathrm{A}_{2}$. It has been reported that caper hydroalcoholic extract prevents the expression of inflammatory cytokines such as TNF $\alpha, \mathrm{IL}_{1} \beta, \mathrm{IL}_{6}, \mathrm{LTB}_{4}$, superoxide anion, and $\mathrm{IL}_{4}(20)$. 
In the pathology section of the present study, the dose of $100 \mathrm{mg} / \mathrm{kg}$ of caper hydroalcoholic extract reduced inflammatory infiltration, increased fibrosis tissue, increased epithelial thickness, and increased muscle tissue. But at the dose of $20 \mathrm{mg} / \mathrm{kg}$, a decrease in fibrous tissue, increased inflammatory infiltration, and decreased thickness of the epithelium and muscle tissue was observed. It seems that caper is effective in tissue repair and preventing pain and inflammation. The compounds in the caper extract also promote the growth of fibroblasts.

In this study, no statistically significant difference was observed between the groups in terms of blood vessel density. We assume that more accurate results will be obtained by increasing the sample size and application of specific immunohistochemistry staining with markers for the identification of blood vessels. Other studies have shown that caper hydroalcoholic extract increases pre-synaptic terminals of inflammatory neurotransmitters and the opening time of these terminals that leads to an increase in the level of related chemical mediators. Caper inhibits function of $\mathrm{NF}_{-\mathrm{K}} \mathrm{B}, \mathrm{COX}_{1}$ and $\mathrm{COX}_{2}$, and reduces pain by increasing noradrenaline in the hippocampus (8). Since the function of mast cells and eosinophils in the antinociceptive effect of caper is still unknown, we used Toluidine blue and Congo red for the identification of mast cells and eosinophils. A reduced number of mast cells was observed at the dose of $100 \mathrm{mg} / \mathrm{kg}$, but the difference was not statistically significant. We assume that more accurate results may be obtained by increasing the sample size. With present results, it seems that the role of mast cells in antinociceptive effect of caper is more prominent than the eosinophils. Due to the lack of eosinophils presence in the samples, it can be said that eosinophils play a role in allergic hypersensitivity and parasitic infections (16). Mast cells are an important source of inflammatory mediators and cytokines, which promote the inflammatory and vascular changes (11). Caper at a dose of $100 \mathrm{mg} / \mathrm{kg}$ could produce antinociceptive effects by reducing the number of mast cells. Since caper reduces the oxidative stress, it can prevent the main contributing factors of tissue damage by preventing the production of free radicals. This effect of caper is due to having high levels of quercetin. Caper also has an antioxidant effect and can produce an antinociceptive effect by inhibiting nitric oxide $(11,20)$.

\section{Conclusions}

The results of the present study suggest that hydroalcoholic extract of caper possesses antinociceptive activity in a dose-dependent manner and caper-induced antinociception might be mediated, at least in part, by anti-inflammatory effects.

\section{Acknowledgments:}

The authors of the present study especially thank Mr. Sheikhzadeh for his cooperation in laboratory function on mice.

\section{Conflict of Interest:}

There is no conflict of interest to be declared.

\section{Authors' contributions:}

Conception or design of the work (SS, SK, RA); Acquisition of data (SS, MA, AM); Analysis or interpretation of data (HG). All authors contributed in drafting or revising the manuscript. All authors read and approved the final manuscript.

\section{References:}

1) Romero-Reyes M, Uyanic JM. Orofacial Pain Management: Current Perspectives. J Pain Res. 2014; 7: 99115. doi: 10.2147/JPR.S37593. PMID: 24591846, PMCID: PMC3937250.

2) Okeson JP. The Classification of Orofacial Pains. Oral Maxillifac Surg Clin North AM. 2008; 20(2): 13344. doi: 10.1016/j.coms.2007.12.009. PMID: 18343320.

3) Iwata K, Takeda M, Bae Oh S, Shinoda M. Neurophysiology of Orofacial Pain. Contemp Oral Med. 2017; 1-23. doi: 10.1007/978-3-319-28100-1 8-2.

4) Conti PC, Pertes RA, Heir GM, Naseri C, Cohen HV, Araujo codos R. Orofacial Pain: Basic Mechanisms and Implication for Successful Management. J Appl Oral Sci. 2003; 11(1): 1-7. doi: 10.1590/S167877572003000100002. PMID: 21409332.

5) Benyamin R, Trescot M, Datta S, Buenaventura R, Adlaka R, Sehgal N, et al. Opioid Complications and Side Effects. Pain Physician. 2008; 11(2): 105-20.

6) Howboldt J. Adverse events associated With NSAIDS. US pharm. 2008; 33(12): 5-13.

7) Moutia M, El Azhary K, Elouaddari A, Al Jahid A, Jamal Eddine J, Seghrouchni F, et al. Capparis Spinasa. Promotes Anti-Inflammatory Response in Vitro through the control of cytokine gene expression in human 
Peripheral Blood Mononuclear Cells. BMC Immunol. 2016; 17(1): 26. doi: 10.1186/s12865-016-0164-x. PMID: 27483999, PMCID: PMC4969972.

8) Zhou H, Jian R, Kang J, Huang X, Li Y, Zhuang CH, et al. Anti-Inflammatory Effects of CaPer (Capparis Spinosal). Fruit Aquenus extracted and isolation of main phytochemicals. J Agricultural and Food Chem. 2010; 58(24): 12717-21. doi: 10.1021/jf1034114. PMID: 21105652.

9) Ninomiya K, Mastuda H, Kubo M, Morikawa T, Nishida N, Yoshikawa M. Potent anti-obese principle from Rosa canina. Bioorg Med Chem Lett. 2007; 17(11): 3059-64. doi: 10.1021/jf1034114. PMID: 21105652.

10) Raboisson P, Dallel R. The orofacial formalin test. Neurosci Biobehav Rev. 2004; 28(2): 219-26. doi: 10.1016/j.neubiorev.2003.12.003. PMID: 15172765.

11) Tajik M, Seifi S, Feizi F, Kazemi S, Moghadamnia AA. Histopathological evaluation of hydroalcholic extraction of capparis spinosa on the oral wound healing in rats. Babol univ Med Sci. 2016; 18(12): 26-32.

12) Rezaee-Asl M, Sabour M, Nikoui V, Ostadhadi S, Balehtiarian A. the study of analgesic effects of Leonurus cardiac L. in mice by formalin, trail flick and hot plate tests. Int Scholarly Research Notice. 2014. doi: 10.1155/2014/687697. PMID: 27433501, PMCID: PMC4897125.

13) Shojaii A, Motaghinejad M, Norouzi S, Motevalian M. Evaluation of anti- inflammatory and analgesic activity of the extracted and fractions of astragalus hamousus in animal models. Iran J pharm Res. 2015; 14(1): 263-69.

14) Khan A, Hargreaves KM. Animal models of orofacial pain. Mol Biol. 2010; 617; 93-104. doi: 10.1007/978-1-60327-323-7_8. PMID: 20336416.

15) Mohtasham N, Babakoohi S, Salehinejad J, Montaser Kouhsari L,Shakeri MT, Shojaiee S, et al. Mast cell density and angiogenesis in oral dysplastic epithelium and low and high grade oral squamous carcinoma. Acta odontol scand .2010; 88(5): 300-4. doi: 10.3109/00016357.2010.494622. PMID: 20586672.

16) Seifi S, Ghafori M, Askian R, Ephtekharian SH, Bijani A. Comparing eosinophil density in dental follicle, follicular cyst and keratocystic odontogenic tumor. J Mazandaran Univ Med Sci. 2018; 28(160): $161-65$.

17) Gandomani MZ, Forouzandeh Malati E. Evaluation of protective efficacy of Avicennia Marina (forssk)vierh leaves against complete freudnds adjuvant-induced arthritis in wistar. Iran J Pharm Res. 2014; 13(3): $945-51$.

18) Arslan R, Bektas N. Antinociceptive effect of methanol extract of capparis ovata in mice. Pharm Biol 2010; 48(10): 1185-90. doi: 10.3109/13880201003629323. PMID: 20819022.

19) Shen SC, Lee WR, Lin HY, Ko HC, Yuang LL, Cohen YC. In vitro and invivo inhibitory activities of rutin, wogonin and quercetin on lipopolysaccharide induced nitric oxide and prostaglandin E2 production. EUR Pharmacol. 2002; 446(1-3): 187-94. doi: 10.1016/S0014-2999(02)01792-2.

20) El Azhary K, Tahiri Jouti N, El Khachibi M, Moutia M, Tabyaoui I, El Hou A, et al. Anti-inflammatory potential of capparis spinosa $\mathrm{L}$. in vitro in mice through inhibitation of cell infiltration and cytokine gene expression. BMC Complement Altern Med. 2017; 17: 81. doi: 10.1186/s12906-017-1569-7. PMID: 28143472, PMCID: PMC5282892. 